\title{
Sergio Bravo y tendencias del montaje
}

Film Editing Tendencies in Sergio Bravo's Filmography

Pablo Corro Pemjean

Instituto de Estética. Pontificia Universidad Católica de Chile. Santiago pcorro@uc.cl

Resumen • El texto ahonda, en términos, críticos tanto en la singular doctrina sobre el montaje cinematográfico propuesta por Gilles Deleuze en sus textos sobre cine, como en el sentido y forma que adopta el montaje en la filmografía del documentalista chileno Sergio Bravo Ramos. Las escuelas de montaje, que distingue el filósofo y que, como escuelas cinematográficas nacionales son asimiladas a conciencias estético-políticas, se identifican en los documentales de Bravo y permiten distinguir a través de sus aplicaciones, una oscilación de la retórica del cineasta, entre la ampliación del inventario de objetos culturales y sociales del cine documental chileno y la experimentación plástica a partir de ellos mismos.

Palabras clave: Sergio Bravo Ramos, montaje cinematográfico, Gilles Deleuze.

Abstract • This article examines critical concepts related to Gilles Deleuze's singular doctrine about film editing, as well as the particular form and meaning of editing techniques developed by Chilean documentary maker Sergio Bravo Ramos throughout his filmography. The quality of film editing schools, acknowledged by Deleuze as political aesthetic consciousness, can be recognized in Bravo's documentaries, and by means of its applications, it is possible to distinguish an oscillation of his rhetoric from the widening of the cultural and social objects inventory in Chilean documentary cinema to artistic experimentation developed from them.

Keywords: Sergio Bravo Ramos, Cinematographic Montage, Gilles Deleuze. 
En el libro Teorías del cine documental chileno: 1957-1973 (Corro et al.2007), los autores sostienen que la aparente diversidad temática y retórica de las películas del periodo y de las diversas instituciones productoras se unifica en el interés por lo que se transforma, lo que se desarrolla, lo que se manifiesta como proceso. Los procesos más demandantes del interés cinematográfico documental en Chile en ese periodo son los procesos de transformación estructural, y, en cierta forma, ideológica de la nación y el estado. Transformación primero del estado, transformación estructural, luego transformación de la nación y transformación ideológica, como propósito de más largo aliento. Tal vez se pueda establecer la relación al revés si consideramos que para ver, para comprender lo real como un proceso, la conciencia misma debe predisponerse para el movimiento, el espíritu debe descomponer unidades en partes, organismos en sistemas, en sistemas con relaciones de diverso tipo, oposiciones permanentes, dialécticas que se resuelven mediante síntesis, es decir que concluyen, o mejor, y para no contradecir la expectativa de dinamismo perpetuo de los sistemas culturales, que pasan a otro modelo de relaciones.

La estructura retórica más propicia para dar cuenta de las transformaciones es el montaje. Reconsideremos qué significa este recurso. A nivel productivo audiovisual se trata de la operación de selección, armado u ordenamiento de un material filmado (o grabado) con el objetivo de construir la versión definitiva de un filme. La definición del montaje como ordenación narrativa y rítmica de los elementos objetivos del relato, enfatiza sus posibilidades retóricas. A través de él se ordenan las acciones que constituyen una historia no sólo para abreviar las largas duraciones existenciales, literarias e históricas y adecuarlas al tiempo cinematográfico, a su brevedad, estandarizada por razones económicas y de costumbre receptivo-perceptiva, sino que especialmente para que la articulación de esas acciones, partículas dramáticas, de esos cuadros visuales vivos, adquiera una organización dinámica, formalmente expresiva, rítmicamente compuesta por las confrontaciones entre cortes existenciales con duración diversa, con velocidades interiores afines o contrastantes, con espacios semejantes o diferentes según las cualidades figurativas, las cantidades y ordenamientos de elementos en su interior.

En el cine de montaje, la especificidad del sentido dramático, el tono emotivo, y la intensidad de los conflictos depende más que de la apropiada segmentación del relato en secuencias y planos ajustados narrativamente, de la organización de la serie de las duraciones de éstos y de una articulación que afectivamente ascienda y descienda, que acelere y desacelere, y que valore las acciones críticas mediante la disposición precedente y sucesiva de situaciones pausadas, acciones morosas. En el montaje se advierte que el sentido es efecto del tiempo y del cambio.

Las doctrinas que relacionan la identificación del potencial discursivo y representacional del cine con la hegemonía y eficacia del montaje son las mismas que interpretan el montaje como una aplicación narrativa y estética de la conciencia simultánea del mundo propia del burgués de comienzos del siglo $\mathrm{XX}^{1}$.

Los filósofos e historiadores de influencia marxista como Walter Benjamin o Arnold Hauser, discípulo éste de Giorgy Lukacs, interpretan la reflexividad de la conciencia burguesa en el montaje identificando en ello 1 retórica del gusto por la sustitución, o la nivelación materialista de hombres y cosas en los planos que sucesivamente se articulan como sistemas plásticos en tensión. Desde una perspectiva ideológica común, pero más sensible a la pretensión burguesa de síntesis, el célebre guionista del Neorrealismo italiano Cesare Zavattin señala en su texto Tesis sobre el Neorrealismo, que: en cuanto al estilo, en sentido estricto, me parece típico del neorrealismo el carácter analítico de la narración, en oposición al sintetismo burgués: sentido analítico
El montaje avanza, desde su primera función narrativa, hacia otra dinámico-rítmica y luego a una plástica ideológica, y lo hace desarrollando una conciencia instrumental de sus materiales al identificarlos simultáneamente como partículas argumentales, duraciones, sistemas materiales con dinámicas y fisonomías específicas. Esa conciencia instrumental que administra las cosas como objetos de sentido y recursos formales de cuadro, y de cuadro en movimiento, es un efecto del pensamiento burgués, de su conciencia económica, y a la vez que saca rendimiento semántico a la brevedad del relato, complementa o realiza ese rendimiento por la efectividad sensorial e ideológica de la disposición del discurso audiovisual. La conciencia que concibe simultánea e interdependiente la actividad económica, política, cultural y material de infinidad de sitios en el mundo, administra, para su propio provecho, la circulación entre esos centros y define, haciendo de ese mapa y dinámicas abreviadas lo más gravitante del mundo, el perfil y comportamiento de lo existente (Corro, 2008).

En la historia del cine y en la historia de las cinematografías nacionales esa identidad formal entre conciencia burguesa, conciencia moderna y articulación estructural del discurso es posible sólo cuando abunda el movimiento en torno a la conciencia fílmica, cuando se impone como movilidad mecánica, férreamente articulada y productiva, y cuando todas las distancias del mundo virtualmente se abrevian merced a los sistemas de telecomunicaciones que hacen de éste mismo mundo una especie de sistema mecánico, también férreamente articulado y productivo.

En los primeros cines casi no hay montaje, o no lo hay más que en el modo de las vistas.

Remontémonos a uno de los arcaicos del cine chileno, al filme Santiago 1920, imágenes encontradas ${ }^{2}$. En este cortometraje, realizado por un autor anónimo, y con motivaciones inciertas, probablemente con el propósito de promocionar la Capital de Chile, bajo los últimos influjos festivos y modernizantes del primer centenario de la República, como una capital occidental y moderna, se presentan vistas de la ciudad.

Usamos la noción de vistas en el sentido de postales, especie de cuadros cinematográficos, con carácter testimonial, y escasamente narrativos. Así han denominado algunos autores a las primeras películas Lumière ${ }^{3}$. No es imposible que este registro haya tenido que ver con las máquinas y procedimientos de esa casa cinematográfica que, es sabido, difundió rápidamente el cine vendiendo a cualquiera y para cualquier destino su aparato con una suerte de pack de película virgen y cortometrajes Lumière. Santiago 1920 presenta vistas del centro, de la Alameda de las Delicias, registradas desde el Cerro Santa Lucía. El inventario de las edificaciones y objetos, que incluye la Casa Central de la Universidad de Chile, el Club de la Unión, el edificio del Congreso Nacional, la Bolsa de valores, la Escuela de Ingeniería de la Universidad de Chile, el Museo de Bellas Artes, la Estación Mapocho de trenes, la primera locomotora de Sudamérica que unía Caldera con Copiapó, se realiza como continuidad de la presencia del elemento humano con todas las reducciones que cada uno sepa y quiera La síntesis de la burguesía era el mejor bocado, el corazón del filete; así, los cineastas tomaban lo exquisito de la vida, los aspectos más representativos de una situación de bienestar y de privilegio (Romaguiro y Ramio, Joaquín; Alsina, Homero. (1993). Textos y manifiestos del cine. Madrid: Cátedra).

Película de autor desconocido, adquirida a un restaurador privado y restaurada por la entonces División de Cultura del Ministerio de Educación, actual Consejo del Arte y la Industria Audiovisual vinculado al ministerio de la Cultura, durante el gobierno del Presidente Ricardo Lagos, en el marco del festejo de los cien años del cine en el 2005.

Cfr. Aumont, Jacques. El ojo interminable, (1997). Barcelona: Paidós. 
mediante planos fijos, o en el mejor de los casos, a través de panorámicas, y con carteles en francés. Seguramente la película estaba destinada a su exhibición en el extranjero en representaciones diplomáticas de Chile.

Las filiaciones entre el filme y la conciencia burguesa como conciencia modernista se reconocen por la naturaleza de los objetos, efectos institucionales representativos de un estado occidental y moderno, de una democracia, de una nación ilustrada, bien provista tecnológica y militarmente, culta según los cánones académicos. El carácter heredado de ese discurso, su mimetismo, el disfraz de nación europea, hace que la película sea especialmente cerrada, despoblada y rígida. Los planos en general son cerrados, abarcan sólo el edificio, el monumento, puesto que es probable que los espacios contiguos no dieran cuenta de la continuidad de lo moderno, sino que más bien prolongaran esa esquirla de modernidad hacia un llano pre-moderno, una ciudad baja colonial con techos de tejas, con carretas de bueyes y una que otra altura de campanario. La desolación se debe a que no aparecen personajes en los paisajes, no hay pueblo habitando esos parajes, seguramente por la misma razón anterior, porque las apariencias del pueblo chileno no pueden pasar por europeas como sí pueden hacerlo las fachadas de los edificios públicos. La rigidez se debe a la limitación del montaje que no es otra cosa que la compaginación de las vistas en función de un criterio que verifica en la capital la existencia de representaciones de diversas entidades ilustradas: edificios públicos del gobierno, de la educación, del comercio, de la cultura, de los transportes, monumentos patrióticos, fiestas ciudadanas, desfiles militares, ejercicios ecuestres.

En esta interpretación la clausura y la desolación serían causas de la rigidez del montaje, o más bien de la inexistencia de este recurso si lo concebimos como una elaboración formal de la compaginación. El encierro del plano dijimos que corresponde a la desigual distribución de la modernidad material en el espacio. La presencia de lo nuevo no es amplia, no se ha difundido por todo el ámbito urbano, más bien lo contrario. Y la soledad resulta de la intención de despoblar el espacio de elementos raciales, sociales, no identificados con la población característica de los enclaves modernos. Las imágenes de Santiago 1920, por esta disposición, tienen una lentitud de tiempo real, a veces de imagen fija. Recordamos dos planos cargados de dinamismo cuyas fuentes móviles son vehículos motorizados, el agente dinámico moderno por excelencia. Una de ellas corresponde a un desfile de autos durante un carnaval de primavera, el otro es una vista en picada de la fachada y los estacionamientos de la estación Mapocho. En la primera imagen el movimiento es lento por efectos de la muchedumbre enfiestada y en la segunda además de autos que entran y salen algunos tranvías atraviesan horizontalmente el encuadre. Pese a esos elementos móviles no podría ser calificado el plano como dinámico.

En relación con los dinamismos espectaculares del cine de género hollywoodense, y de los movimientos monumentales, épicos del cine realista soviético, ambos efectos del montaje, de diversas doctrinas y estrategias de éste, pero, en suma, efectos de ese dispositivo, el cine chileno hasta fines de los cincuenta es lento, rígido. La timidez relacional de sus representaciones, la linealidad de sus estructuras, y la morosidad de sus formalizaciones dramáticas y plásticas creemos que se debe a una cuestión de orden histórico paradigmático, o geopolítico: que hasta entonces el medio revela una escasa evidencia y conciencia materia de la modernidad circundante, y, como caso particular de ello, una reducida cantidad de elementos dinámicos en el espacio próximo.

Antes nos referimos al largometraje El Húsar de la muerte (1925) de Pedro Sienna, y lo hicimos para señalar efectos de proximidad realista entre los elementos dramáticos caracterizadores y sus referentes histórico-culturales, proximidad como identidad. Ahora bien, el filme de Manuel Rodríguez nos sirve para considerar en una matriz genérica de orden épica, en un esquema dramático de aventuras, la presencia aún trabada del montaje. Si bien en la película muda hay carreras a caballo, duelos de esgrima, saltos acrobáticos del protagonista, esas formas activas no producen mayor agilidad en el relato. Tal vez porque mayoritariamente se presentan en planos generales y de larga duración, bajo el esquema de: una acción, un plano, un cuadro. Habrá relativa agilidad dramática, y motivación dinámica cuando Sienna incorpore en el relato el montaje paralelo. Esto sucede en dos secuencias, una inicial en que el oficial realista San Bruno ridiculiza en el salón de una casona de santiaguinos monárquicos las acciones rebeldes del agitador independentista Manuel Rodríguez. En el montaje, mientras el oficial anuncia ante un grupo la pronta captura de Rodríguez, fuera de la casa, el guerrillero contempla la escena, y sin descender de su cabalgadura escribe en un pequeño papel una nota de provocación rebelde, la atraviesa luego con un puñal el que a continuación arroja y ensarta en el interior del salón. La otra escena es la del sarao en que los realistas celebran la llegada del nuevo gobernador Casimiro Marcó del Pont. Manuel Rodríguez se infiltra en la fiesta disfrazado de un tal Conde de Torre Tagle, mientras, siguiendo sus instrucciones, su ayudante, el Huacho Pelao, en una habitación contigua, se roba el baúl que contiene la primera acta de la Independencia de Chile. El montaje paralelo, pese a lo largo de cada plano, tiene alguna aceleración dramática, patética, puesto que termina, en una parte, con la huida del Huacho Pelao, y en la otra, en el espacio interior, con la revelación pública de su identidad por parte del guerrillero y la huida tras una atrevida proclama independentista.

En 1920, luego en 1925, en tiempos de El Húsar de la Muerte, después en 1940, o aún a comienzos de los '50, el cine chileno no acoge las velocidades del mundo circundante, ni las expresiones de actividad simultánea, sistemática, dialéctica, de la realidad histórica social contingente, porque eventualmente estos mundos o realidades no poseen esos fenómenos, no se exponen con velocidad y sistema en un grado suficiente como para desbordar formas y tensiones hacia el plano reflexivo del cine.

A fines de la década del cincuenta la Historia de Chile se acelera. La metáfora de la velocidad la proyectamos sobre la Historia, comprendida ésta como un proceso dramático. En tal caso son las acciones del drama de Chile las que toman prisa hacia el enlace y el desenlace. El enlace es la confrontación de diversos actores cuya aspiración es la de transformar o perpetuar el estado de las cosas, estado institucional, material, político, social y cultural. El desenlace es, tras la intensificación de los conflictos y el choque de los agentes dramáticos en un combate, la instauración de un orden más o menos permanente, la imposición de un paradigma sobre otro.

El desenlace del proceso de radicalización y choque de los proyectos de Nación y Estado chileno fue el Golpe de Estado y la instauración de la Junta Militar de gobierno. El enlace tal vez sea todo el largo periplo republicano que las clases media y baja, o, más propiamente, el pueblo, realizan desde 1925 con Arturo Alessandri, con los presidentes radicales, en pos de su representación gubernamental y finalmente de la conquista del poder en 1970, con Salvador Allende y la Unidad Popular en La Moneda.

Pero la etapa visualmente acelerada del enlace se inicia en la segunda mitad de la década de los cincuenta.

Las mayorías populares, organizadas políticamente en sindicatos, partidos, comités, y volcadas en los espacios públicos, formando marchas, desfiles y mítines, procurando la redistribución de las tierras agrícolas, la obtención de viviendas dignas o la conquista de 
terrenos urbanos para la edificación de éstas, la nacionalización de las materias primas productivas y la democratización de las universidades, constituyen un referente caracterizador o legitimador de los diversos proyectos gubernamentales. Esa legitimación es un fenómeno de autoconciencia, de auto-reconocimiento, de auto-contemplación, y de representación discursiva que cuenta con los antiguos y nuevos medios audiovisuales para su ejecución. Antiguo el cine, nueva la televisión.

El cine, especialmente el documental, registra muchos de los procesos sociales nombrados y distingue, como su nuevo protagonista, a las masas, al pueblo, insertándose más efectivamente en la realidad a través de ese expediente dramático.

La televisión, que también irrumpe, a través de la Pontificia Universidad Católica de Chile, y Católica de Valparaíso, en el año 1959, dará inicio a su gestión de paradojal contribución a la movilidad y fijeza del mundo y de las conciencias multiplicando las representaciones de lo real, ampliando y diversificando sus centros de acción, y restringiendo progresivamente toda disposición existencial y cultural a la de la novedad, y más tarde, del consumo ${ }^{4}$.

Desde el tiempo de Las Callampas, de Rafael Sánchez y Mimbre de Sergio Bravo, ambos documentales de 1957, hasta 1973, el cine chileno se identificará retóricamente con el montaje puesto que a través de él no sólo se expresa la inusitada y conflictiva multiplicación de las posibilidades de organización teórica y práctica de la vida individual y especialmente de la colectiva, sino que además se manifiesta el cambio como un valor y el sistema como el principio estructural de todo.

En las comprensiones del montaje como forma dominante en la retórica del cine de los Sesenta y del Nuevo cine chileno se distingue sistemáticamente la función de la dialéctica: simbólica, ideológica y material. La clase alta enfrentada con las clases populares o con la clase obrera, lo estático opuesto a lo dinámico, lo natural a lo artificial. Estos atributos y defectos forman parte de la figuración de lo simultáneo como tensión conflictiva entre términos sociales y culturales o como elementos contiguos, contradictorios pero indiferentes entre sí, enajenados. La simultaneidad y la dialéctica se expresan en el montaje paralelo y la resolución de los conflictos en el montaje ascendente. Ejemplos excepcionales de estas estructuras se encuentran en los documentales Venceremos (1970) de Pedro Chaskel, en Descomedidos y Chascones (1972) de Carlos Flores, y a nivel de largometrajes argumentales, y mediante una estructura de compaginación de planos y secuencias más largas en su alternancia, en Morir un poco de Álvaro Covacevic (1967), o en Largo Viaje de Patricio Kaulen (1967). Estas formas son representativas de aquella comprensión orgánica y binaria de la realidad que caracteriza a muchas teorías del montaje. Las más importantes de éstas como la del proto-cine hollywoodense, identificado con la obra y estrategias de D.W. Griffith,

Sobre la identificación progresiva del cine chileno con el movimiento, el cambio, el conflicto y el sistema, como una asimilación de las extrovertidas y más conflictivas dinámicas de la historia y con el aumento material, tecrico, nas cambio y movimiento en las reflexiones sobre el estatuto de la conciencia en las obras de Husserl y Bergson, postulados cercanos entre sí que contradicen lo que venín sosteniendo las filosofís y sicologías idealistas y empiristas hasta ese momento: cada uno lanzaba su grito de guerra: toda conciencia es conciencia de algo (Husserl), o más aún, toda conciencia es algo (Bergson). Es indudable que muchos factores exteriores a la filosofía explicaban que la antigua posición se hubiese vuelto imposible. Eran factores sociales y científicos que ponían cada vez más movimiento en la vida consciente, y cada vez más imágenes en el mundo material. ¿Cómo no tomar en cuenta entonces al cine, que a la sazón estaba en sus preámbulos y que llegaría a aportar su propia evidencia de una imagen movimiento? (Deleuze, 2008: 88). y la de la escuela formalista soviética, asociada a la filmografía y pensamiento de Serguei Eisenstein, sistematizan y desarrollan esta visión de mundo como sistemas en oposición. En estas teorías como en las aplicaciones del montaje en el cine chileno que ahora consideramos, lo real y su estructura binaria, sistemática pero dialéctica, es la realidad social, y cuando las tensiones se expresan en confrontaciones materiales, plásticas, formales, temporales, lo hacen como refuerzo del modo específico de las relaciones dramáticas, de las formas de convivencia entre los hombres.

Durante este periodo, las materias primas del montaje son las figuras y formas protagónicas del mundo histórico, grupos, individuos, materias y artefactos como útiles o índices de propiedad. El montaje no aventura el estudio de las dialécticas fenoménicas como ocasiones de experimentación lingüística y plástica del medio expresivo. Dada la gravedad y el alcance que tiene lo político en todos los ámbitos de la vida social no hay actividad que no esté sometida a las demandas del compromiso. Este reclamo es particularmente fuerte en el cine. Son tantas y tan vertiginosas las formas del cambio en los escenarios públicos que el cine y su atención simultánea no pueden más que ocuparse de su registro directo, y los efectos de esos cambios tienen consecuencias tan determinantes para la existencia de lo colectivo y lo individual, para las delimitaciones y sentido de la libertad, de la cultura, de la subsistencia, que las elaboraciones discursivas, los énfasis retóricos, expresados entre otras formas a través del montaje se limitan a la expresión de la identificación ideológica, de la militancia. La estética es superflua, suntuaria, lujo de privilegiados, de enajenados. La posibilidad de figurar las dialécticas históricas a través de dialécticas de las materias primas del mundo fenoménico, luz, movimiento, tiempo, o de acceder mediante su consideración experimental a la certeza de la dialéctica misma como principio estructurador de todo lo existente, implica un ejercicio de abstracción en doble sentido difícil de haberse cumplido en aquellos años. El sentido doble de la abstracción es primero el descubrimiento de que en el cine la representación del mundo histórico pasa por la administración del mundo fenoménico, y que en esa articulación se infiltra y juega la subjetividad, juego delicado que arriesga abstraerse del asunto contingente hasta el punto de sustituir la historia por la estética. La otra dimensión es una variante casi indiscernible de la anterior, o un momento de ella, que es la abstracción de las filiaciones institucionales, militantes, partidistas, que restringen la progresión de la conciencia cinematográfica hacia las evidencias plásticas de los fundamentos operativos de lo existente, mediante los reclamos de urgencia realista, objetivadora, y a través de un pauteo ortodoxo de la forma y el sentido.

Una obra cinematográfica en la que se expresan excepcional y ejemplarmente las diversas formas del montaje señaladas es la del documentalista chileno, Sergio Bravo Ramos (1927).

Para identificar las distintas formas y doctrinas del montaje presentes en la obra de Bravo, particularmente en sus películas Mimbre de 1957, Día de organillos de 1958, Láminas de Almahue de 1962, Banderas del pueblo de 1964, y La Glane de 1985, echemos mano de una rara pero rica taxonomía del montaje en el sistema de los textos de teoría del cine, que es la de Gilles Deleuze en su libro La imagen-movimiento (2008).

En el capítulo número tres, dedicado al montaje, el filósofo francés distingue cuatro tendencias que caracteriza también como cuatro escuelas: la tendencia orgánica de la escuela americana, la dialéctica de la escuela soviética, la cuantitativa de la escuela francesa de preguerra, y la intensiva de la escuela expresionista alemana.

Deleuze relaciona la escuela americana con el cine de David Griffith y la explica sintéticamente señalando que el cineasta: 
Concibió la composición de las imágenes-movimiento como una organización, un organismo, una gran unidad orgánica. Su gran hallazgo fue ese. El organismo es ante todo una unidad en lo diverso, es decir, un conjunto de partes diferenciadas: están los hombres y las mujere, es rices los

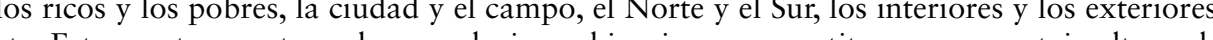
etc. Estas partes son tomadas en relaciones binarias que constituyen un montaje alternado paralelo donde la imagen de una parte sucede a la de otra de acuerdo con un ritmo [...] es preciso también que las partes actúen y reaccionen unas sobre otras, para mostrar de qué modo entran en conflicto y amenazan la unidad del conjunto orgánico, y a la vez de qué modo superan el conflicto o restauran la unidad (Deleuze, 2008: 52-53).

Pasemos de inmediato a lo esencial de la definición del montaje en la escuela soviética: Eisenstein sustituye el montaje paralelo de Griffith por un montaje de oposiciones; el montaje convergente o concurrente por un montaje de saltos cualitativos ("montaje a saltos”). Toda clase de nuevos aspectos de montaje se conjugan en él, o más bien fluyen de él en una gran creación, no sólo de operaciones prácticas, sino de conceptos teóricos: nueva concepción del primer plano, nueva concepción del montaje acelerado, montaje vertical, montaje de atracciones, montaje intelectual o de conciencia Nosotros creemos en la coherencia de este conjunto orgánico patético; y aquí radica sin duda lo esencial de la revolución de Eisenstein: él dota a la dialéctica de un sentido propiamente cinematográfico, arranca al ritmo de una sola evaluación empírica o estética, como sucede en el cine de Griffith, concibe el organismo como algo esencialmente dialético (Deleuze, 2008: 61).

No será en las primeras películas de Bravo donde veremos presentes estas doctrinas, que concurren en la concepción orgánica de la realidad social pero que se distinguen en la resolución de sus conflictos, puesto que en Griffith la estabilidad se recupera tras las confrontaciones de los términos individuales en el duelo y Eisenstein, que concibe el conflicto de los términos como el modo específico e inevitable de su relatividad sistemática, deriva de las luchas colectivas aquel "salto cualitativo" que es la variación del "Todo".

Los materiales del montaje, como materiales dramáticos, componentes sociales individuales e institucionales, aparecen, al menos en las películas de Bravo que, por ahora, son relativamente accesibles, como Banderas del pueblo (1965), filme de apoyo propagandístico a la candidatura presidencial de 1964 de Salvador Allende.

La película no presenta duelos, esquiva la forma predominante de la representación de las dialécticas políticas y sociales al final de la década, que es la de exponer en el montaje paralelo las contradicciones de las realidades que viven ricos y pobres, como en aquella impresionante secuencia de ese otro documental identificado con los ideales de la Unidad Popular, Venceremos, en que Chaskel nos presenta por un lado a los burgueses y sus perros en un certamen de adiestramiento y belleza canina y por otro lado vemos la apariencia de varios recién nacidos raquíticos en una maternidad. Banderas del pueblo es una película que más bien ignora la figura de las oligarquías y se propone hacer del pueblo el protagonista único de la historia, historia que se identifica con el devenir de Chile mismo. Banderas del pueblo es la reescritura de la historia de Chile, desde la perspectiva de la izquierda, en función de sus acciones y procesos. Pese a esto no está exento el conflicto de clases de la retórica del filme, más bien lo contrario, se expresa intensivamente en el comienzo para dejar sentado el precedente que el antagonismo o la beligerancia es uno de los motores del movimiento de la Nación.

Nos referimos a la obertura de fotomontaje de la película. Las imágenes fotográficas, seguramente de origen periodístico, presentan mediante oposiciones de planos generales y primeros planos una lucha callejera entre manifestantes y la fuerza pública, la que no se llega a ver pero sí se revela por la presencia de las humaredas de las bombas lacrimógenas. La intensidad del conflicto a nivel sonoro está formalizada por un redoble de tambores y por la insistencia, en la estructura ascendente del montaje, que va abreviando la duración y la amplitud de los planos, en la figura de un herido, un bulto gris que otros manifestantes señalan. Esa dialéctica interna pasa a formar parte de otra mayor a nivel secuencial, puesto que la película da paso a la presentación secuencial de Pablo Neruda recitando para la cámara un poema militante. El poeta como sujeto individual, la poesía misma como motor no contrario sino complementario de la lucha callejera, y el registro continuo, la imagen en movimiento, el tiempo activo, hacen el contrapunto a los recursos de la secuencia de obertura. Contra el montaje, contra la fragmentación, la continuidad; contra el efecto musical del tambor en sonido over, el doblaje del sonido directo, la voz del poeta. Contra la multitud anónima, el sujeto individual, excepcional, ejemplar, Neruda; contra las imágenes aparentemente contingentes, no premeditadas; la acción dispuesta para la cámara. El principal poeta del Frente Popular declama un poema como una consigna:

Pongo tu mano en mis hombros. Como viejos amigos, te digo en las orejas: ven, no sufras, ya llega el día. Ven con todos los que a ti se parecen, los más sencillos, ven, no sufras, ven conmigo, porque aunque no lo sepas, eso yo si lo sé, yo sé hacia dónde vamos y es esta la palabra, no sufras porque ganaremos, ganaremos nosotros los más sencillos, ganaremos,

A continuación se desarrolla una relación entre personajes y acontecimientos, en su mayoría provenientes de materiales de registros cinematográficos que Bravo utiliza como recursos documentales de carácter testimonial y uno que otro plano ejecutado por él mismo.

En este relato épico de la historia del avance del pueblo chileno hacia condiciones de reconocimiento y autodeterminación hay numerosos héroes, eventualmente, figuras del duelo, como instancia gráfica de la puesta en riesgo del equilibrio de la sociedad como ente orgánico y binario. Luis Emilio Recabarren, Elías Lafferte, Pedro Aguirre Cerda. Pero también están los hitos dramáticos a través de los cuales la historia salta cualitativamente, en el modo del combate o no. La matanza de la Escuela Santa María de Iquique. Imágenes referenciales del surgimiento del Partido Demócrata, del Partido Obrero Socialista, del Partido Comunista, del Partido Socialista. Y entre ellas numerosas imágenes de sistemas sociales y productivos dinámicos, por su actividad articulada como movimiento objetivo, o como partícula dramática según la lógica de la narración, todos conjuntos mecánicos.

Vistas de la pesca industrial en el norte, grúas enormes que sostienen y vierten en las cubiertas de los barcos la masa en agitación de los pescados; la imagen de un pobre violinista callejero al que unos espectadores tan miserables como él mismo le echan unas pocas monedas en su tarro; militantes que conversan en la puerta de la sede de un partido político; el plano general de una tronadura en algún yacimiento de la gran minería chilena; imágenes de máquinas de los minerales, de grandes camiones y de un pájaro enjaulado. Entonces el narrador que administra libremente la referencialidad o la ambigüedad de las imágenes dice en ese momento "el pueblo avanza; pueblo con capacidad y personalidad en el trabajo y en el combate".

En el montaje de Bravo, eventualmente, se expresan heredadas como atavismos aprehendidos de la experiencia del cine, las estructuras de la oposición, las metáforas, en menor medida, la presentación más interpretativa, por efectos del discurso explícito del narrador, que por relaciones dramáticas y plásticas, de formas activo-reactivas, del esquema de estímulo-respuesta, o de situación-acción-reacción. Pero contra esas influencias irremediables 
de la fórmula griffitheana, que por lo demás tenía sentido no desatender del todo puesto que se trata de la primera película que Bravo hace, en teoría, para conquistar los favores ideológicos de un público masivo, estaban las poéticas elementales, como metáforas de ilustración doctrinal, típicamente eisensteniana, y esas pequeñas y marginales figuraciones de cosas y cortes formales, materiales, sociales, desestimados por el cine: el pájaro enjaulado, el violinista, la gente en las fachadas de las casas, un grupo que gravemente mira en plano medio hacia la parte baja del encuadre, como mirando a un muerto que nunca se ve.

En el libro Teorías del cine documental chileno: 1957-1973, ya en la introducción los autores establecen las afinidades objetivas entre la valoración que hace el cineasta ruso Dziga Vertov del intervalo en el montaje y el tratamiento que darán estos cines a nuevos objetos y sujetos sociales, desatendidos por la tradición representacional, como motivos interválicos propicios para la ampliación de la conciencia cinematográfica chilena. Esas pequeñas formas de la realidad que distinguimos en el montaje de Las banderas del pueblo, ingrávidas y contingentes a la vez, son el material interválico de Bravo, partes de su comprensión sistemática y mecánica de lo existente:

La originalidad de (Dziga) Vertov, estriba en la afirmación radical de una dialéctica de la La oreria en sí misma [.. ] no hay duda de lo que Vertov mostraba era al hombre presente la mater natura

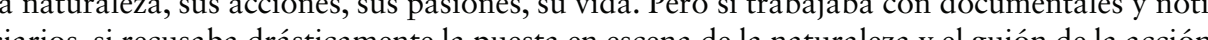
ciaros, sirecusaba drástica sus pacción, era por una razón perta cada uno hasta la canpesina nás encantadora o el nino nás connovedor, se presentaba como un sistema material en perpetua interaccion. Eran catalizadores, convertidores, transformadores que recibían y devolvían movimientos cambiando su velocidad, su dirección, su orden, haciendo que la materia progresara hacia estados menos probables, realizando cambios sin común medida con sus propias dimensiones. No es que para Vertov los seres fuesen máquinas, sino que más bien las maquinas tenian corazón y "corrían, temblaban, se sobresaltaban y echaban chispas" como también podía hacerlo el hombre, con otros movimientos y bajo otras condiciones, pero siempre en interacción unos con otros. Lo que Vertov descubría en el noticiario era el niño molecular, la mujer molecular, la mujer y el niño materiales, tanto como los sistemas o denominados mecanismos o máquinas. Lo importante eran todos los pasajes (comunistas) desde un orden que se deshace hacia un orden que se construye pero entre dos istemas o dos órdenes, entre dos movimientos, está necesariamente, el intervalo variable. En Vertov, el intervalo de movimiento es la percepción, el vistazo, el ojo. Pero el ojo no es el del homre de co per hión dal que está en a a percepción tal que está en la nateria, tal que se extiende desde un punto en que comienza recorriendo el universo y palpitando a la medida de sus intervalos (Deleuze, 2008: 64-65).

La conciencia, que establece relaciones argumentales y formales en Las Banderas del pueblo, trata a las máquinas, los paisajes, los edificios y los hombres, como un sistema material en perpetua interacción. Mientras se ejercita esa conciencia en el montaje narrativo o de ideas, practicando con sentido materialista una inusitada versión del devenir histórico de Chile, en la práctica de la disponibilidad de los materiales es ella misma la que se conoce como libre para ensayar aún en ese ámbito de lo político las posibilidades plásticas de las formas cinematográficas.

En Las Banderas del Pueblo en el minuto 7 con 11 segundos el director incorpora la imagen de lo que parece ser el reflejo, naturalmente invertido sobre la superficie de un río, de un arbusto, o de un árbol, acaso de un espino o de un algarrobo. Inmediatamente antes de ese plano el documental presenta una especie de fosa, como un sepulcro, sobre un suelo árido y después el sol poniéndose en el horizonte en el desierto. Luego, cuando una cámara hace un travelling lateral veloz con ese mismo paisaje de fondo y el narrador dice: "la llamarada se extiende hacia el sur, el agua no apaga el fuego del pueblo arriero, montañés y huaso", el documental muestra grandes ríos y un puente ferroviario que podría atravesar el río Bío-Bío. Después aparece, como una señalética vial, un escudo que índica la ciudad de Laja, que pende de un cable tendido sobre la carretera. Sigue a esta imagen otra más gratuita, más insignificante en el plano informativo pero más sugerente en términos formales, la imagen de la trama vegetal sobre el agua, el entramado arbóreo, efecto de contraluz. ¿Qué significa esa imagen en la película de apoyo a la candidatura de Salvador Allende? Nada, o ¿cosas tan abstractas o ambiguas como el recordatorio gráfico de la historia y de la nación como tramas, estructuras arborescentes, cuadros de tensiones cruzadas que achurando el plano, componen una forma?

Esta imagen nos permite volver hacia atrás en la filmografía de Bravo y considerar cómo es posible encontrar en él conexiones en su práctica del montaje con aquellas teorías propuestas por Deleuze y caracterizadas por el interés en las intensidades de luz y cantidades de movimiento. Nos referimos respectivamente a Mimbre (1957) y Día de organillos (1958). Antes de entrar en digresiones sobre esas películas y esas prácticas de montaje conviene señalar que la imagen del reflejo del entramado vegetal sobre el agua es un ícono fuerte en la obra de Bravo, que tal vez en Las Banderas del pueblo no se articula nítidamente con los otros ejemplos argumentales, pero que trabaja para su obra general en el dominio poético de las metáforas del agua y las metáforas vegetales. Metáforas vegetales, articuladas con las dinámicas de la luz en Mimbre; metáforas vegetales y de agua, reunidas serenamente en Láminas de Almahue y catastróficamente en La respuesta ${ }^{5}$ (1961). Poéticas vegetales y del agua en La Glane, filme sobre la masacre de la población de un pueblo francés sobre el Ródano ejecutada por una tropa de SS. a fines de la Segunda Guerra Mundial, reunidas para figurar simultáneamente la irreductible subsistencia de la naturaleza a la destrucción de los hombres, con el fin de servir de memorial de la obcecación de la vida, y el flujo de la historia que es también el devenir de la existencia, la trascendencia de la vida, en la figura de las aguas del río.

Mimbre, a la vez que representa el comienzo de la obra madura de $\mathrm{Bravo}^{6}$, constituye la obra inaugural del Cine Experimental de la Universidad de Chile. El cineasta era entonces alumno de arquitectura de esa casa de estudios ${ }^{7}$. En el marco de las entrevistas de la investigación que dieron fundamento al libro Teorías del cine documental chileno: 1957-1973 (2007), Sergio Bravo expresó que su interés por el cine se vio fuertemente estimulado por los cursos sobre la arquitectura de la Bauhaus que recibieron por esos años. En el referido libro, cuando los autores tratan de esclarecer el sentido de la noción de materia prima del

El documental La respuesta fue dirigido por el historiador Leopoldo Castedo. Sergio Bravo fue parte de equipo ocupándose de la fotografía del filme y, en parte, del trabajo de cámara. Si bien la estructura expositiva, clásica de la película da cuenta de la concepción histórica del guión, como reflejo de la condición de Director, muchas de sus imágenes y del montaje, ilustran la intervención estética e ideológica de Bravo en el proyecto.

El director señala la existencia de un filme previo, de un ejercicio cinematográfico dedicado al cañón del Cerro Santa Lucía.

(1959) y junto a quien fundó el Cine Experimental de la Universidad de Chile. 
cine como factor caracterizador de teorías cinematográficas, distinguen entre materias primas existenciales, por ejemplo, el mundo histórico o el mundo de lo imaginario, y materias primas fenoménicas, por ejemplo, el movimiento, la luz, el color. En virtud de esta doctrina y de esa filiación intermedial o interdisciplinaria señalada por Bravo, los autores ejemplifican que la materia prima del cine de Bravo, al menos en Mimbre sería el movimiento y la luz, materias primas, presumiblemente propias también del movimiento Bauhaus.

Mimbre, tal como se señala en sus carteles de obertura, da "a conocer las impresiones visuales que sacuden al visitante que llega a su taller", al taller del artesano mimbrero llamado "Manzanito". Se trata entonces de una película sobre las impresiones de luz que capta el cine en el proceso de enhebrado y tejido creativo de la fibra vegetal. Nada más alejado a un documental de índole costumbrista, o didáctico folklorista. En honor a la verdad, la película podría prescindir de todo lo que no sean los movimientos del mimbre blanco en vara libre o trenzado contra los fondos mate, grises, negros del patio soleado de la vieja casa taller de Abtao 275, Quinta Normal. Podría prescindir del rostro de Alfredo Manzano, "Manzanito", incluso de sus manos, en las que uno no llega advertir la potencia dinámica, eléctrica, estridente de las varas en tratamiento. Incluso podrían faltar, sin perjuicio de la sensación final que produce el montaje, los planos en que figuran las formas terminadas, canastos con forma de pescado, de vacas, de floreros, porque esa sensación es la de la agitación de una vida luminosa orgánico inorgánica anterior o posterior a una formalización instrumental. Si no fuera porque el movimiento no puede prescindir de uno de sus estados, del reposo, si fuera discernible sin intervalos de reposo, esos planos, que, por cierto, contienen menos movimientos que los de las hebras en las manos o en e aire cortando el plano negro como si se tratara de un filme abstracto de Hans Richter ${ }^{8}$, o simplemente de aberraciones eléctricas en una pantalla de televisión de puntos luminosos, serían innecesarios. En correspondencia con este espíritu relativamente informalista, o abstracto de la película, la música que compuso para ella Violeta Parra, con la autonomía formal que goza, y que el montaje no procura forzar a la analogía, tiende una y otra vez a la estridencia punzante (atonales), entre armonías (tonales) de reminiscencias folklóricas.

Para no forzar demasiado las cosas, ni ajustar las formas con las teorías al punto de desnaturalizar una u otra, las relaciones que establecemos entre el montaje de Bravo en Mimbre con el montaje expresionista -la más extraña de las formas sobre la compaginación que aporta Deleuze a las taxonomías estructurales del cine- se derivan de la siguiente enunciación:

Podríamos contraponer punto por punto la Escuela francesa y el Expresionismo alemán. Al "más movimiento", le responde un “¡más luz!”. El movimiento se desata pero al servicio de la luz, para hacerla centellear, formar o dislocar estrellas, multiplicar reflejos...la luz es ciertamente movimiento, y la imagen-movimiento y la imagen-luz son las dos caras de un misma aparición. Pero si la luz era hasta ahora un inmenso movimiento de extensión, en el expresionismo se presenta como un poderoso movimiento de intensidad, como el movimiento intensivo por excelencia (Deleuze, 2008: 77).

Deleuze opone en varios sentidos el montaje de la Escuela francesa de preguerra con el Expresionismo alemán. El inmenso movimiento extensivo de la luz era el de la formación dinámica, coreográfica y por momentos épica -por ejemplo, en Abel Gance- de aquella tendencia de montaje, o incluso podría ser encarnada por los espacios monumentales en conflicto de la obra de Eisenstein, posterior al expresionismo según la cronología ortodoxa de Lotte Eisner ${ }^{10}$, por ejemplo, en Alexander Nevsky (Eisenstein,1938) y especialmente en Iván el terrible en donde encontramos grandes afinidades con el Fausto (1926) de Murnau.

En Mimbre, tal como dice Deleuze, el movimiento se desata pero al servicio de la luz, para hacerla centellear, formar o dislocar estrellas. Pocas veces las palabras de otros nos son tan oportunas, efectivamente, el movimiento se ata y se desata, se trata del ejercicio de anudar, de tejer, y ese movimiento, definido por la luz polarizada en la película blanco y negro, centellea por momentos en los planos breves del mimbre en primer plano trazando el encuadre, como esquirlas de una materia incandescente. En cuanto a multiplicar reflejos se trata de descomponer la luz, cosa que sucede en Mimbre pero sin espejos, cuando la cámara entra en los conos y cilindros de mimbre y una mano invisible desde afuera los hace girar al sol se producen efectos caleidoscópicos tan bellos y menos artificiosos que los de Fernand Leger en El ballet mecánico (1924), efectos tan desconcertantes visualmente que en los tejidos de luz y sombra se puede invertir la percepción de lleno y vacío.

La intensidad a la que se refiere Deleuze debe ser asimilada dentro del plano convencional del concepto, la luz como movimiento de intensidad, juego de amplias gradaciones expresivas holgado en la estrechez del espacio material, y cuyo despliegue considera sin cálculo las hondas resonancias afectivas de la concreta, aunque, cinematográfica, virtualidad formal de la luz y el movimiento.

En el documental de Bravo, que corresponde a una forma del llamado "documental de observación”, en nuestra opinión, de una modernidad artística todavía incuestionable ${ }^{11}$ las relaciones que establece Deleuze entre intensidades de luz y movimientos de ascenso y caída, no vienen al caso, puesto que no hay materia argumental para las reminiscencias míticas o axiológicas que se manifiestan, por ejemplo, en las obras de Paul Wegener, Friedrich Murnau, Robert Wiener, o Fritz Lang ${ }^{12}$.

Sin embargo, esa relación no estará reñida con la obra de Bravo todo el tiempo. En $\mathrm{La}$ Glane $^{13}$ (1988), la reformulación expresiva de las materias a través del montaje, agua, vegetales, piedras, será un movimiento desde lo inerte a lo dinámico y viceversa, proceso que estaba ya en las imaginerías del expresionismo, por ejemplo en el motivo del Golem. Pues, tal como en aquella conciencia cinematográfica, o, más bien, visión de mundo, donde esas metamorfosis de la materia implican tensiones axiológicas, conflagraciones descomunales entre el bien y el mal figuradas por las relaciones entre la luz y las sombras, las que, según

Abel Gance (1889-1981). Cineasta francés, célebre por sus largometrajes históricos, el más popular de todos, el drama épico Napoléon (1927).

(1) es La pantalla demoniaca (1965), estudio estético, ideológico e histórico del referido movimiento cinematográfico.

11 El investigador del cine latinoamericano Paulo Antonio Paranaguá, en el libro Cine documental en América Latina (2003. Madrid. Cátedra), donde interviene como editor, incorpora a Mimbre en el limitado inventario de los más notables documentales de la región.

12 Todos grandes exponentes cinematográficos del expresionismo alemán. Sus obras más representativas de esa tendencia cinematográfica son, respectivamente, El Golem (1915), Nosferatu (1922), El gabinete del Doctor Caligari (1920), Metrópolis (1927).

13 El documental La Glane procura reconstruir mediante antecedentes históricos pero esencialmente a través de una exploración de motivos físicos residuales, vestigios materiales, la matanza de los habitantes del poblado La Glane sûr L'Oradour ejecutada por una división SS en 1944 mientras se libraba la batalla de Normandía. 
la naturaleza y el estado del conflicto, estarán más o menos delimitadas, del mismo modo que en La Glane, desde la niebla densa a la luz plena, desde el gris al color intenso, desde la silueta desperfilada al accidente más delineado de la materia, a los procesos expresivos de los elementos, que transmiten conmociones de la vida y la muerte, despliegues del bien y del mal, más por el modo en que Bravo las articula figurativa, rítmica, dramáticamente en el montaje, que por la narración que hace el guía oficial del sitio del martirio.

Las relaciones entre las formas del montaje presentes en los filmes documentales de Sergio Bravo y la modalidad que le reconoce Gilles Deleuze a la del cine francés de preguerra, "escuela francesa" dice él, se manifiesta con mayor nitidez en su filme Día de organillos (1958).

Antes de este ajuste teórico, el cine francés se nos filtró ya en las poéticas de la compaginación de Bravo a través de la alusión que con fines de identidad y diferencia hicimos a El ballet mecánico de Fernand Leger, película que el mismo Deleuze particulariza en esta tendencia de montaje para señalar que en cierto sentido ella corresponde a:

un arte abstracto donde el movimiento puro se desprendía unas veces de objetos deformados, por abstracción progresiva, y otras, de elementos geométricos en transformación periodica, con un grupo de transformación afectando el conjunto del espacio. Era la búsqueda de un cinetismo como arte propiamente visual, y que ya en el cine mudo planteaba el problema de una relación de la imagen-movimiento con el color y con la música (Deleuze, 2008: 69).

Se trata entonces de una forma de montaje, en este caso, el de Leger, no narrativa, particularmente seductora para una conciencia pictórica contemporánea, abstracta, específicamente de abstracción geométrica. El cinetismo, y la abstracción geométrica en e cine, como sucedáneos materiales y experimentales del color y la luz para los pintores, y fotógrafos de las vanguardias, constituyen también pertrechos materiales, instrumentales para las conciencias coreográficas, teatrales y arquitectónicas disidentes de la primera mitad del siglo, luego vías de acceso expresivo y poético en un medio que les ofrece concretas y diversas formas de la duración.

Pues bien, insistimos que en tiempos de Mimbre y Día de Organillos Bravo era estudiante de Arquitectura, y que para efectos de las caracterizaciones intermediales, es un cineasta-arquitecto

La otra infiltración de lo francés en el cine de Sergio Bravo se manifiesta en su identificación concreta y a la vez poética con la historia reciente de Francia a través del episodio del documental La Glane.

Identificarse quiere decir en este caso la promoción, o búsqueda de un procedimiento de penetración existencial, de aproximación corpórea y de conciencia, al efecto residual de una tragedia humana concreta, fechada, situada, por más relativamente remota que esta resulte del tiempo y la cultura del realizador. Expediente fenomenológico el de interrogar a las piedras de los muros, de los suelos, de las bóvedas, a las calles vacías, las casas en ruinas, los postes y sus cableados, a las materias más duras y cultivadas, y a las quebradas y deformes. Es parte también de esa epoché fenomenológica, fibra de ese mismo tejido de sentido, el de los fenómenos naturales y humanos, circunstanciales y permanentes, indiferentes, inmunes en apariencia al caos: las aguas grandes y chicas de los ríos y riachuelos de la región de Lemosin, las arboledas, los pescadores en los remansos, la cosecha de las manzanas, la elaboración de la sidra. Cuando decimos que se trata de una infiltración de lo francés en Bravo, o que Bravo se inmiscuye en Francia, lo decimos, en la primera dimensión simple que se trata de un trabajo francés, un documental por encargo para la televisión francesa. Es probable entonces, que el director haya pensado en ese espectador, en las imágenes que ha visto sobre sus propios padecimientos, en las que quiere y puede ver aún. Esa cautela es conciencia audiovisual como presunción en la que puede converger la identidad y la diferencia. La semejanza con el Resnais de Noche y Niebla (1955), y la diferencia de toda convención sobre los martiriologios en el plano audiovisual al aceptar que uno de sus hijos incorporara una composición electrónica de Brian Eno. La identificación de la que hablamos se construye a través de cierta articulación material de los residuos y los suplentes, de las duraciones y las distancias en la interrogación material. Ese contacto fenomenológico con el acontecimiento parte o culmina en el sentido cinematográfico de esa comunidad. No por imitación de un efecto o de una fórmula ideológica se recrean en La Glane, con frecuencia más dilatada, los paralelismos, entre la actividad creadora de los hombres y la destructora, entre la cultura y el mal, o la locura como uno de sus estadios, que ya estaban en Noche y Niebla, en la narración de Alain Resnais y en la música que aporta Hans Eisler para ésta película. Se vuelven a crear porque eso afirma la siempre desconcertada atención a las coexistencias del mal, con sus efectos, al poder creativo de los hombres y la regularidad de la naturaleza.

Lo que dice Deleuze de la escuela francesa de montaje es que "se trata de autores interesados sobre todo en la cantidad de movimiento, y en las cantidades métricas que permiten definirla" (Deleuze, 2008: 66).

La ciudad, la capital, la metrópolis, es el mundo que elije el joven Bravo para experimentar diversas cantidades de movimiento y someter diversos objetos convencionales a transformaciones semánticas a través de la alteración de sus dinamismos acostumbrados.

La mayoría de los filmes del director explorarán la luz el movimiento y sus mecanismos en el mundo campesino, en el mundo rural, o en la confrontación de naturaleza y técnica en circunstancias y emplazamientos límite. Trilla (1954), Láminas de Almahue y Mimbre, corresponde al primer sistema, y también se incluye su largometraje de ficción No eran Nadie (1981). La Respuesta y Aquel Nguillatún (1960-2000), al segundo sistema. Esto no impide que se relacionen a través del montaje el movimiento con el mecanismo, tal vez se trata de una indagación más primaria, que incluye pensar las tensiones iniciales motivadoras entre naturaleza y técnica, entre naturaleza y déficit operativo humano, y que por lo mismo se interesa en máquinas primarias, tecnologías arcaicas, procesos de domesticación: molino de agua, y fabricación de ruedas de carreta en Mimbre; domesticación de las plantas y de los animales en Trilla; sometimiento de la fibra dura y uniforme a la plasticidad creativa y multiforme en Mimbre; desagüe del río Riñihue en su límite de desborde, re-encausamiento de las aguas catastróficas en La Respuesta (1960), y la misma intención de aplacamiento y domesticidad por medios religiosos, rituales en Aquel Nguillatún.

La opción de la ciudad es para concentrarse en la movilidad misma, en sus diversas formas, en sus diversas fuentes, en la acumulación dinámica pero como efecto figurativo, en su despliegue como música, música para los ojos. Luego el artefacto ha sido convocado más para que componga en el montaje ajustes formales a desarrollos coreográficos.

Sobre la relación mecanismo-coreografía o piezas articuladas-bailarines, en esta doctrina de montaje señala Deleuze:

Una danza colectiva tiene, claro está, una composición orgánica de los bailarines y una composición dialéctica de sus movimientos, no sólo lentos y rápidos, sino también rectos circulares. Pero al tiempo que se reconocen estos movimientos es posible extraer o abstraer de ellos un solo cuerpo que sería "el" bailarín, el cuerpo único de todos los bailarines (Deleuze, 2008: 66-67). 
Así como en el comienzo del filme de Bravo, los ordenamientos y riñas de las gentes que buscan agua y las bandejas de plata que acarrean el té matinal al interior de mansiones, coinciden con el sueño de los niños callejeros en las aceras, uno de los motivos de Vertov del despertar de una ciudad en El hombre de la cámara, en Día de Organillos los niños sin casa que ejecutan bailes coléricos en plena calle, los planos móviles en cámara lenta, dolly in en diversos ángulos, del avance de un carro de mano, o el equilibrio de un limpiador de ventanas en un departamento elevado, y luego la vista descendente que reproduce el desplome del hombre a la acera, conectan con las coreografías de la mujer que asciende y desciende en el columpio, con la vieja que asciende una y otra vez una escala con un canasto, con los caballeros que bajan a gran velocidad por el tobogán de una feria de atracciones en El ballet mecánico de Leger.

En función de estas figuras y de los ritmos de las compaginaciones inmediatas y de los de las secuencias, como alternancias de inercias, "se rebasan los móviles para extraer un máximo de cantidad de movimiento en un espacio dado [...] y en última instancia, la danza sería una máquina y los bailarines sus piezas” (Deleuze, 2008: 67).

Día de organillos es, por ahora, nuestro más nítido ejercicio cinematográfico de sinfonía de ciudad, como lo fue para el cine de Alemania, Berlín, sinfonía de una ciudad de Walter Ruttmann, o para el cine ruso, El hombre de la cámara de Vertov, y para Brasil, Sao Paulo, sinfonía de una metrópolis (1929). La relación entre movimiento productivo, o movimiento destructivo, cuyos efectos pueden ser la miseria, el predominio de la calle como único lugar de asiento, el trabajo miserable, y la muerte por el riesgo de las tareas, tanto en Bravo como, por ejemplo, en Leger, deriva de un motivo rico en circulaciones y en efectos de ellas, el de la circulación del dinero. Pocos cines han compuesto tan consistentes sociologías cinematográficas del dinero como el francés. Basta por ahora con identificar uno de los últimos filmes de Bresson, El dinero (1983).

En Leger están las monedas formando figuras contra un fondo negro y remitiendo al carácter generador de mecanismos, de espectáculos baratos que tiene la abreviada pieza de transacción. En Día de organillos están también las monedas en aquella secuencia en que éstas caen del cielo para el organillero que toca en una esquina que podría ser la de la calle Miraflores con Esmeralda. La lluvia no es un milagro sino la limosna que a modo de juego niños burgueses arrojan desde un balcón al músico pobre y a su ayudante, una mujer vieja que recoge con cansancio las chauchas. La secuencia es precedida por otra en que unas máquinas aplanadoras y unas especies de martillos apisonadores achatan un terreno, aplanan una calle para ser pavimentada. El movimiento vertical descendente aplasta para la circulación y la subsistencia miserable.

Hasta acá, esta exégesis de las políticas del montaje en el cine documental de Sergio Bravo, interpretación que es una apología de su genio constructivo y de su excepcional sentido plástico e ideológico de las relaciones formales en el mundo concreto.

El realismo de este documentalista, por razones históricas, cronológicas, por el tiempo en que desarrolla su estilo, descubre sus objetos y despliega su experticia en el montaje y la fotografía, antes de 1965, es decir, antes de la hegemonización de lo político de todos los sentidos en Chile, se identifica con las bases estructurales de los procesos materiales, de los procesos de la forma, que son anteriores a las cristalizaciones de los procesos discursivos, retóricos, e iconográficos de expresión de los procesos sociales.

La riqueza y diversidad del montaje de Bravo no es un efecto de diletantismo o mimetismo productivos, sino el resultado de una exploración concentrada, focalizada sistemáticamente, de las virtualidades semánticas y plásticas de las apariencias del mundo en el cine, luego, el resultado de la investigación obstinada de las capacidades poético epistemológicas del medio expresivo.

Este programa particular de investigación y expresión de Sergio Bravo es causa y efecto de su reconocida, obcecada, voluntad de autonomía, de independencia de trabajo, a veces de soledad, de contrariedad, de suspicacia.

$\mathrm{Al}$ maestro le fue concedido merecidamente el premio Pedro Sienna en el año 2006 pero tal reconocimiento no recompone la relación tangencial, marginal o contraria de Bravo en el sistema de los cineastas que le son contemporáneos, de las instituciones de formación y de producción cinematográfica en las que ayer participó y que hoy resurgen.

\section{REFERENCIAS}

Corro, Pablo; Larraín, Carolina; Alberdi, Maite; Van Diest, Camila. (2007). Teorías del cine documental chileno, 1957-1973. Santiago de Chile: Pontificia Universidad Católica de Chile.

Corro, Pablo. (2008). Devenir secular de la simultaneidad en el cine. En Gabriel Castillo Fadic (ed.), Espesores de superficie, Actas del Simposio Internacional de Estética y Filosofía, 2007. Santiago de Chile: Pontificia Universidad Católica de Chile.

Deluze, Gilles. (2008). La imagen-movimiento. Buenos Aires: Paidós.
Recepción: martes 9 de diciembre de 2009 Aceptación: jueves 21 de enero de 2010 